\title{
A Brief History of Microglial Ultrastructure: Distinctive Features, Phenotypes, and Functions Discovered Over the Past 60 Years by Electron Microscopy
}

\author{
Julie C. Savage ${ }^{1,2 *}$, Katherine Picard ${ }^{1,2}$, Fernando González-lbáñez ${ }^{1,2}$ and \\ Marie-Ėve Tremblay ${ }^{1,2 *}$
}

${ }^{1}$ Axe neurosciences, Centre de Recherche du CHU de Québec - Université Laval, Québec City, QC, Canada, ${ }^{2}$ Département de médecine moléculaire, Université Laval, Québec City, QC, Canada

OPEN ACCESS

Edited by:

Diego Gomez-Nicola,

University of Southampton,

United Kingdom

Reviewed by:

Astrid E. Cardona,

University of Texas at San Antonio,

United States

Richa Hanamsagar,

Harvard Medical School,

United States

*Correspondence:

Julie C. Savage

julie.savage.1@ulaval.ca;

Marie-Ëve Tremblay

tremblay.marie-eve@

crchudequebec.ulaval.ca

Specialty section:

This article was submitted to Multiple Sclerosis and Neuroimmunology, a section of the journal

Frontiers in Immunology

Received: 31 January 2018

Accepted: 03 April 2018

Published: 25 April 2018

Citation:

Savage JC, Picard K, GonzálezIbáñez F and Tremblay M-Ë (2018)

A Brief History of Microglial Ultrastructure: Distinctive Features,

Phenotypes, and Functions Discovered Over the Past 60 Years by Electron Microscopy.

Front. Immunol. 9:803. doi: 10.3389/fimmu.2018.00803
The first electron microscope was constructed in 1931. Several decades later, techniques were developed to allow the first ultrastructural analysis of microglia by transmission electron microscopy (EM). In the 50 years that followed, important roles of microglia have been identified, specifically due to the ultrastructural resolution currently available only with EM. In particular, the addition of electron-dense staining using immunohistochemical EM methods has allowed the identification of microglial cell bodies, as well as processes, which are difficult to recognize in EM, and to uncover their complex interactions with neurons and synapses. The ability to recognize neuronal, astrocytic, and oligodendrocytic compartments in the neuropil without any staining is another invaluable advantage of EM over light microscopy for studying intimate cell-cell contacts. The technique has been essential in defining microglial interactions with neurons and synapses, thus providing, among other discoveries, important insights into their roles in synaptic stripping and pruning via phagocytosis of extraneous synapses. Recent technological advances in EM including serial block-face imaging and focused-ion beam scanning EM have also facilitated automated acquisition of large tissue volumes required to reconstruct neuronal circuits in 3D at nanometer-resolution. These cutting-edge techniques which are now becoming increasingly available will further revolutionize the study of microglia across stages of the lifespan, brain regions, and contexts of health and disease. In this mini-review, we will focus on defining the distinctive ultrastructural features of microglia and the unique insights into their function that were provided by EM.

Keywords: microglia, ultrastructure, electron microscopy, correlative light and electron microscopy, 3D ultrastructure

\section{INTRODUCTION}

Microglia are the only immune cells that permanently reside in the brain. Originally believed to mediate inflammatory responses to infection (1), trauma (2), ischemia (3), or neurodegenerative disease (4), recent studies identified microglia as crucial actors in the proper development and maintenance of neuronal circuits (5). del Río-Hortega provided the original morphological description

Abbreviations: 2p, two-photon; EM, electron microscopy; TEM, transmission electron microscope; SEM, scanning electron microscope; DAB, diaminobenzidine; Iba1, ionized calcium-binding adapter molecule 1; CLEM, correlative light and electron microscopy; AD, Alzheimer's disease; SBEM, serial block-face scanning electron microscope; FIB-SEM, focused-ion beam coupled with scanning electron microscope. 
of microglia at the turn of the twentieth century, having modified Golgi's silver stain to identify microglia (6). His manuscripts have recently been translated into English and annotated (7). Early research into microglial physiology prompted researchers to posit hypotheses that still hold true: microglia are phagocytic; they are capable of generating inflammation in response to infection; they may be responsible for some aspects of neurodegenerative disease; they originate outside of the brain and colonize it early in development (8). Between the early twentieth and twenty-first centuries microglia remained mainly uninvestigated as a cell type [reviewed in Ref. (9)], until Davalos et al. and Nimmerjahn et al. uncovered their incredibly dynamic processes in the adult brain under physiological conditions using two-photon (2p) microscopy $(10,11)$. Following this discovery and with the development of genetic tools to specifically identify microglia and their progeny (12-14), high throughput gene-expression analysis (15-18), and investigation into expression of cell surface receptors $(19,20)$, researchers have completed a whirlwind of studies in an attempt to unravel microglial roles in a myriad of healthy and disease processes (21). Recent developments in super-resolution and $2 \mathrm{p}$ microscopy have provided insight into microglial interaction with dendritic spines (22-24). However, genetic manipulations required for marker expression in neurons and microglia can induce cellular stress and impair normal functions (25-27). Electron microscopy (EM) can be used to investigate the unique ultrastructure of microglia and their relationship with synapses, and identify their phagocytic cargo without any immunohistochemical or genetic labeling. While super-resolution microscopy has surpassed the diffraction limit of light microscopy, its resolution is still insufficient to discern samples smaller than $50 \mathrm{~nm}$, especially in the $z$-dimension, and requires specific labeling probes to prevent steric hindrance from influencing the resulting image (28). In this review, we will focus on the use of EM to unravel structural and functional mysteries of microglia and their interaction with healthy and diseased brain tissue.

\section{HISTORY AND DEVELOPMENT OF EM}

Electron microscopy utilizes focused electron beams to illuminate the subject of interest. Since an electron's wavelength is up to 100,000 times shorter than a photon's, EM is capable of resolving atomic structures, while most light microscopes are diffractionlimited to $500 \mathrm{~nm}$ resolution.

Hans Busch, a pioneer in the field of electron optics, laid the theoretical groundwork for EM by determining the motion of electrons in a magnetic field and the potential to focus electron beams (29). The first EM was invented by Knoll and Ruska in 1932, based on the Bush's published theories (30). The first transmission electron microscope (TEM) functioned by projecting electrons through a thin sample and onto film, and investigating the regions of the sample that were electron-permissive versus electron-dense. Shortly after TEMs were developed, the first scanning electron microscope (SEM) was invented in 1940 (31). SEM differs from TEM as it visualizes electrons that are scattered off the surface of the specimen instead of electrons that pass through the specimen.

Over the following three decades, scientists perfected multiple ways to process and preserve biological samples in order to garner useful images of in situ tissue preparations (Figure 1). Aldehyde fixation cross-links proteins in tissues $(32,33)$, while osmium tetroxide fixation mainly preserves lipids and renders membranes electron-dense (34). The development of transcardiac perfusions provided fast delivery of fixatives to deep regions of the brain and

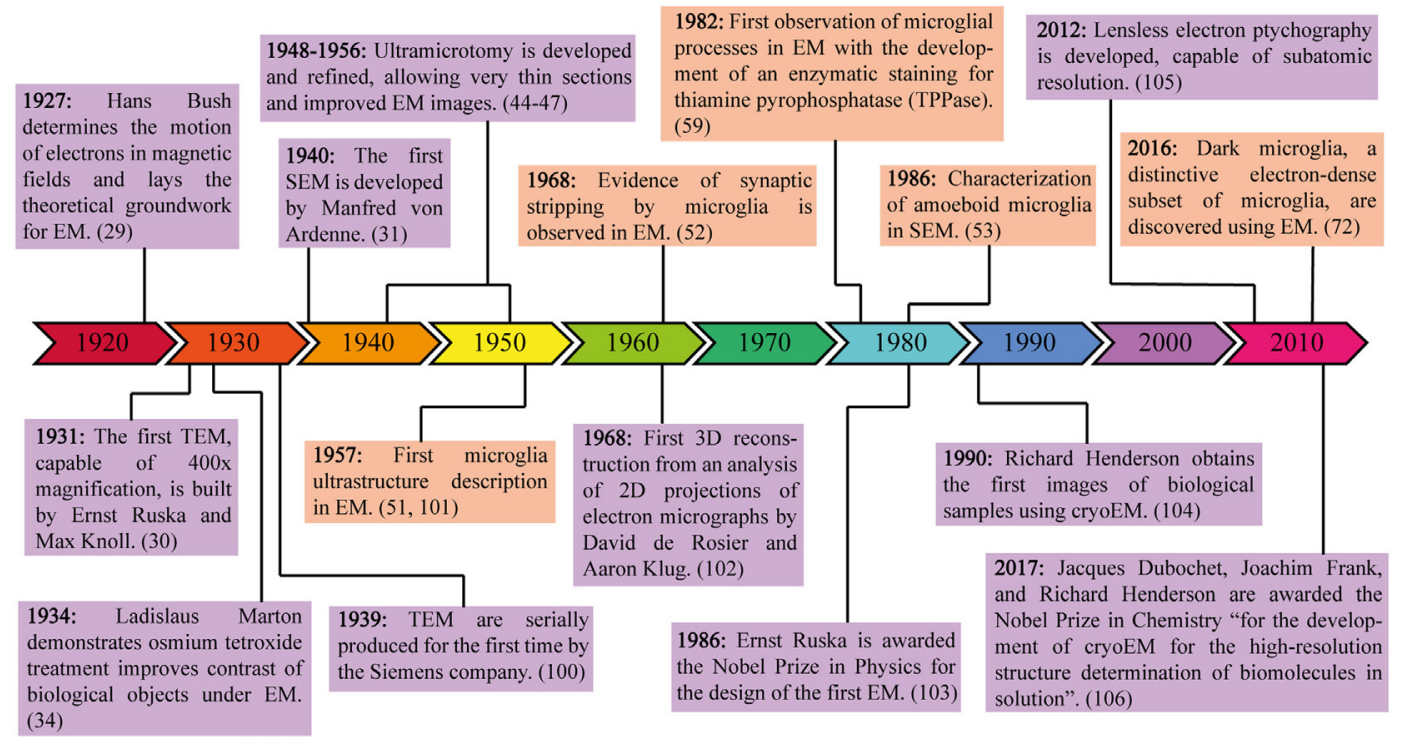

FIGURE 1 | Milestones in electron microscopy (EM) engineering and discovery. This timeline highlights the major theoretical and experimental advances in EM, from the invention of the first electron microscope to the 2017 Nobel Prize in Chemistry for the discoveries leading to cryoEM. Purple frames contain information about the development of technology required for EM, while orange frames contain information about microglial discoveries made possible through the use of EM. 
other biological tissues, arresting any possible degradation that may have occurred in diffusion-dependent fixation techniques (35-37). However, using aldehydes or other fixatives results in tissue shrinkage and loss of extracellular space. This can be avoided by freeze substitution, a type of cryoEM: flash-freezing the tissue of interest followed by fixation performed at very low temperatures (38). Fixing the specimen in buffers that match the osmolarity of the tissue of interest can preserve extracellular space (39). Alternatively, if the specimen and chamber of the EM are kept below $-140^{\circ} \mathrm{C}$, samples can be visualized without any fixation (40,41). Cell viability assays and staining for cell surface markers can be performed on live cells in suspension prior to deposition onto TEM grids and flash-freezing $(42,43)$.

Particularly important for TEM imaging was the development of ultramicrotomy, which allowed ultrathin $(50-80 \mathrm{~nm})$ sections to be cut from larger specimens, thus improving resolution and focus (44-47). These ultrathin sections allowed researchers to visualize ultrastructural images of various biological samples by capturing the transmitted electrons after they passed through the specimen onto films. The conventional protocol to prepare biological tissue for TEM is well explained by several groups (48-50).

\section{EM AND MICROGLIA}

In 1957, the first ultrastructural image of microglia in the rat parietal cortex was published (51), and in 1968, TEM images showed microglia physically separating presynaptic terminals from postsynaptic dendrites or neuronal cell bodies, a term defined as synaptic stripping (52). The first TEM images of microglia uncovered clues to the dynamic nature of these cells, decades before $2 p$ microscopy discovered their movements to survey the brain parenchyma in real-time. Cultured microglia investigated using SEM identified many tiny processes projecting directly from cell somas, and draw stark attention to the two-dimensional stressors placed on cells in culture (53). Pioneering studies in EM identified many unique characteristics of microglial cell bodies, before any cell-specific immunological studies were developed.

Microglial cell bodies can be discerned from those of other cell types by their small size (3-6 $\mu \mathrm{m})$, electron-dense cytoplasm, and characteristically bean-shaped nuclei. They also display a distinct heterochromatin pattern. A thick, dark band of electron-dense heterochromatin is located near the nuclear envelope, with pockets of compact heterochromatin nets throughout the nucleus. These nets are often visualized as small islands of dark heterochromatin within a sea of more loosely packed, lighter euchromatin within the central part of the nucleus $(54,55)$. Microglial cell bodies have a very thin ring of cytoplasm separating their nuclei from their cell membranes, and contain few organelles within a single ultrathin section, but those visible are mostly mitochondria, long stretches of endoplasmic reticulum, Golgi saccules, and lysosomes (54, $56,57)$. They are often phagocytic and contain lipidic inclusions, especially in older animals (58) (Figures 2A,D).

The development of microglial-specific stains compatible with EM has been a major aid in determining their functions in situ. Labeling microglial membranes and cytoplasm, originally with enzymatic reactions and more recently with immunoEM, allowed researchers to investigate microglial processes in animal models and human postmortem tissue $(57,59,60)$. Current immunoEM studies utilize either diaminobenzidine or gold-conjugated antibodies (or colabeling using both) to deposit electron-dense precipitate and identify proteins of interest $(22,61)$. Ionized calcium-binding adapter molecule 1 (Iba1) is often used to identify microglia/macrophages within the brain (62). After much study using immunoEM to identify their main characteristics (22), trained researchers can identify microglial processes based solely on their unique ultrastructure. Microglia's ramified projections are long, thin, and almost never contiguous with their cell bodies in ultrathin sections examined by TEM (Figures 2B,C). They are often in close, direct contact with neuronal cell bodies, or separated only by a very thin astrocytic process $(22,57,59,63)$. A single microglial process can contact multiple synaptic elements, and interacts with axon terminals, dendritic spines, perisynaptic astrocytic processes, and encircles parts of synaptic clefts $(22,63)$. Their processes often perform extracellular degradation, visible as pockets of extracellular space sometimes containing pinpoints of membrane degradation. They frequently contain vacuoles or multivesicular bodies, long stretches of endoplasmic reticulum, and phagocytic inclusions (Figure 2C).

Microglia promote proper neuronal wiring and activity, and EM studies were vital for discovering their role in development and maintenance of functional neuronal connections (21). Elegant EM studies demonstrated that glia (performing the functions of microglia) in Drosophila (64), macrophages and microglia in zebrafish (65), as well as microglia in rodents (66-68) phagocytose degenerating axonal tracts, axon terminal fragments, and dendritic spines during development of the thalamus, cerebral cortex, and hippocampus. Interestingly, no phagocytic interactions between microglia and synapses were identified in TEM studies of a mouse model of prion disease (69), although immunoEM was not performed and microglial processes may have been overlooked. Microglia also phagocytose putative neuronal debris following saponin-induced cholinergic cell death in rats (70). Sequential EM images are required to verify phagocytic cargo is fully enclosed within a microglial process and has been demonstrated for phagocytosis of synaptic elements by both microglia and astrocytes $(22,67,71)$. Automation of sequential EM using knives or focused-ion beams inside SEM chambers can provide nanometer-scale resolution images of microglia in $3 \mathrm{D}$.

Recent TEM studies have uncovered a new microglial phenotype, named dark microglia. These dark microglia share many ultrastructural characteristics (including cell size, immunohistochemical markers, and phagocytic phenotype) with healthy microglia, yet appear strikingly different under TEM. Their cell bodies can be quicklyidentified by their condensed, electron-dense cytoplasm that makes them appear as dark as mitochondria. Dark microglia display many signs of cellular stress, including nuclear and chromatin condensation and dilation of their endoplasmic reticulum (Figure 2F). Additionally, they are present in greater numbers in pathological contexts often associated with neuronal dystrophy and distress. They have been identified in the APP-PS1 mouse model of Alzheimer's disease (AD), aged mice, animals subjected to social defeat stress, fractalkine receptor-deficient mice, and mouse models of schizophrenia $(72,73)$. They show reduced expression levels of some microglial markers, including 

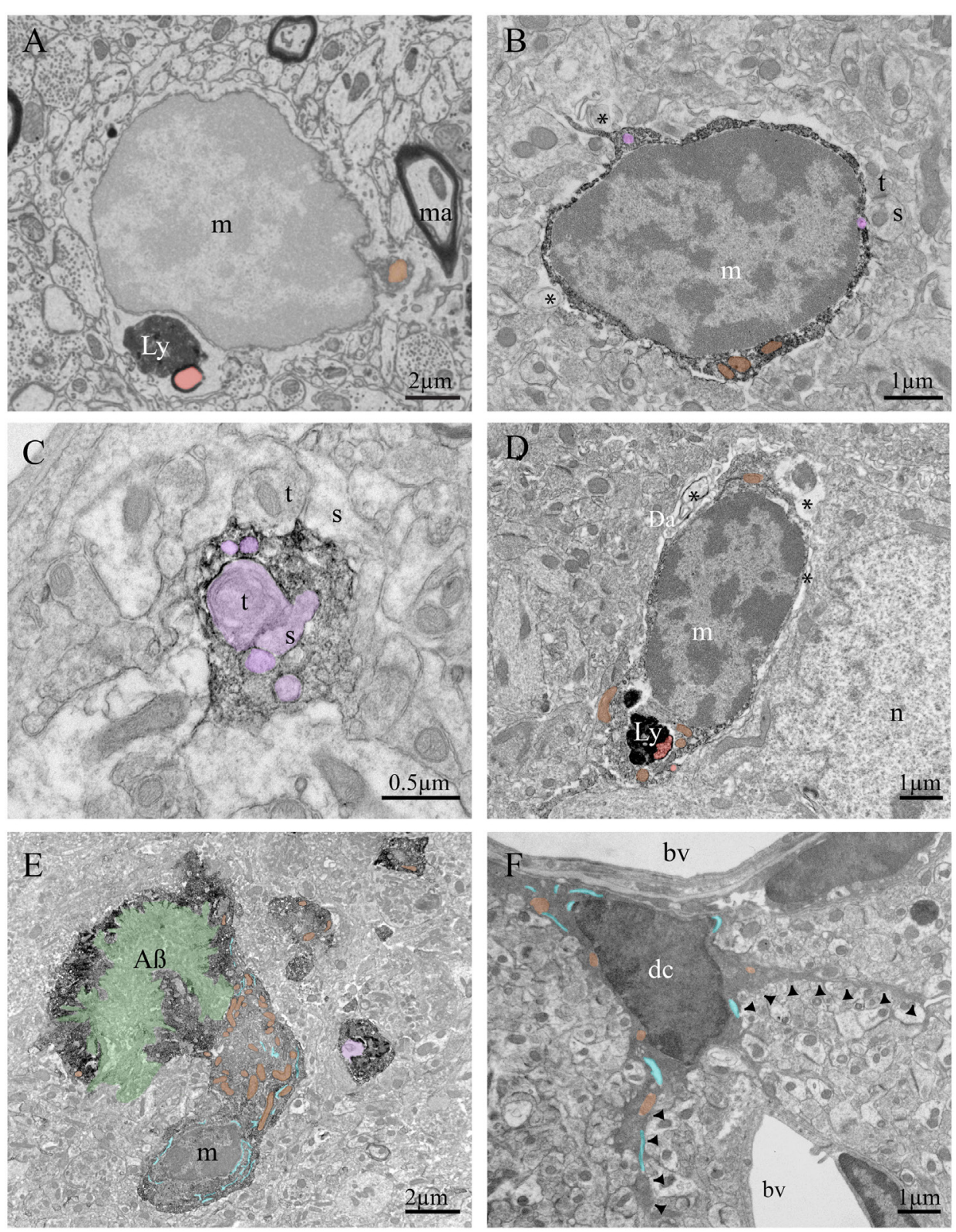

FIGURE 2 | Ultrastructural features of murine brain microglia in health and disease. Example of microglia imaged using a focused-ion beam coupled with scanning electron microscope without any immunostaining (A), containing lipofuscin granules (Ly) and a lipid body (Lb). Diaminobenzidine staining against ionized calciumbinding adapter molecule 1 (lba1) creates a dark immunoprecipitate in the cytoplasm as shown by transmission electron microscopy (TEM) (B-E). Iba1 staining allows identification of microglial processes in fractalkine receptor-knockout mice, for instance, allowing researchers to investigate their contacts with synaptic terminals and study phagocytic inclusions. (B) A microglial cell body in an APP-PS1 mouse is contacting a synapse between two axon terminals and a dendritic spine, as well as juxtaposing cellular debris. (C) A microglial process in a C57Bl/6 mouse contains several inclusions, notably an axon terminal making a synaptic contact on a dendritic spine. (D) A microglial cell body in a mouse model of Werner syndrome juxtaposes myelin debris and contains lipofuscin granules. (E) A microglial cell body in an APP-PS1 mouse is found in intimate contact with an amyloid beta plaque. (F) Example of dark microglia observed by TEM in a stressed fractalkine receptor-deficient mouse, characterized by its dark cytoplasm and thin processes projecting from the cell body (black arrowheads). Symbols and abbreviations: m, microglia; n, neuron; dc, dark microglia; t, axon terminal; s, dendritic spine; bv, blood vessel; Ly, lipofuscin; Da, degenerated axon; ma, myelinated axon; AB, amyloid-beta plaque. Asterisk (*) denotes evidence of cellular debris undergoing digestion in the extracellular space. Pseudocolor code: phagocytic inclusions $=$ purple, examples of dilated endoplasmic reticulum $=$ blue, examples of mitochondria $=$ orange, amyloid-beta plaque $=$ green, lipid bodies $=$ red.

Iba1, but are strongly immunopositive for others, including complement receptor subunit $\mathrm{CD} 11 \mathrm{~b}$ and microglia-specific antibody 4D4. Most dark microglia located near amyloid plaques in APP-PS1 mouse model express TREM2, though dark microglia in other disease models do not. While normal microglia rarely have contiguous processes attached to their somas in ultrathin sections, dark microglia show many long, thin processes encircling dystrophic neurons, wrapping around synaptic structures, 
investing themselves deep into amyloid beta plaques, and interacting with synapses in regions of high synaptic turnover (72). Although they display many signs of cellular stress, they have never been found expressing apoptotic or necrotic cell markers. Dark microglia are often located near blood vessels, which could imply a possible peripheral origin or perhaps a route of egress for the stressed cell to leave the brain parenchyma (Figure 2F). As there is not yet a definitive marker of dark microglia, they can only be investigated with EM, highlighting its relevance in modern microglial biology studies.

\section{CORRELATIVE LIGHT AND ELECTRON MICROSCOPY (CLEM)}

The combination of both light microscopy and EM can be used to uncover more information than either technique individually. CLEM was first used in 1969. Silver staining originally described by Río-Hortega was used to identify and investigate microglia in light microscopy. After confirming microglial-specific staining, researchers investigated ultrathin sections under TEM and published the first description of microglial ultrastructure (54).

Electron microscopy is currently used to unravel details and variations in ultrastructure that cannot be investigated with light microscopy (Table 1). Light microscopy is often used to detect changes in microglial density and morphology in health and disease (74), and to identify particular regions of interest. After identifying a region of interest, such as one affected by hypoxia in stroke or amyloid-beta positive plaque-containing tissue in $\mathrm{AD}, \mathrm{EM}$ can delve further into specific changes in microglial ultrastructure, cellular viability and stress, all without requiring further immunostaining markers $(75,76)$. EM can also reveal structures which are not otherwise visible, and discern subcellular localization of proteins and mRNA using immunostaining, in situ hybridization, or in situ RT-PCR $(57,77,78)$. EM was recently used to clarify microglial process fragmentation observed with light microscopy in postmortem human tissue from an individual suffering from AD. Unexpectedly, EM studies revealed no fragmentation as the two parts of the microglial process were linked by a cytoplasmic bridge, thus invalidating the original hypothesis (79).

Light microscopy can also be performed on living cells prior to investigation with EM to tie temporal information to ultrastructural resolution. The technique used is a specific type of CLEM. Live imaging using $2 \mathrm{p}$ microscopy studies cellular relationships, interactions with the surrounding environment, and intracellular dynamics in real-time; but lacks complex ultrastructural information. These imaging techniques are also limited to genetically encoded or virally introduced cell-specific fluorescent markers, which may introduce phenotypic changes on their own (26). EM can uncover structural information, but the specimen must be fixed (or flash-frozen for cryoEM), and can only be investigated as a snapshot moment in time. CLEM integrates imaging of fluorescent proteins in live cells with the ultrastructural resolution of EM. After live-cell imaging is performed, various fixation and staining techniques can be employed to investigate ultrastructure in the same tissues. van Rijnsoever and colleagues used CLEM to study the endolysosomal system by confocal microscopy followed by cryoEM to image protein structures with nanometer resolution (85). This technique could be used to obtain insight into microglial proteins, phagocytic machinery, and organelle biogenesis.

It is also possible to combine EM with $2 \mathrm{p}$ microscopy. While $2 \mathrm{p}$ studies allow investigation of live microglial interactions with nearby neurons, EM performed afterward can study the intimate contacts between microglia and synaptic elements, and their changes in response to various behavioral experiences and pathologies $(22,63,86-88)$. Light microscopy also informs EM studies, making it much easier to solve needle-in-haystack problems and identify rare events within the neuropil. For example, an Alzheimer's study injected animals with methoxyX04, a blood-brain barrier permeable amyloid-beta fluorescent marker. Researchers then selected sections containing the region of interest known to contain amyloid-beta, thus increasing the likelihood of finding plaque-associated microglia in ultrathin sections (Figure 2E) (50). Similarly, fluorescent microscopy can be used to target a specific microglial population to be analyzed in EM. Bechmann and Nitsch fluorescently labeled axons prior to performing entorhinal lesions and traced the clearance of degenerating tissue by identifying the fluorescent compound within nearby microglia. By focusing EM studies on regions containing fluorescently labeled microglia, they were able to investigate the subpopulation of microglial cells which had phagocytosed degenerating axons (89).

Another CLEM technique is the use of light microscopy in correlation with cryoEM. A study utilizing both techniques recently discovered the native folding of herpes simplex virus as it moved throughout axons. 3D visualization permits analysis of vesicle fusion and actin bond formation (90). CryoEM was also recently used to image Golgi apparati in two different conformations within neurons (91) and investigate minor changes in ultrastructure following intracerebral injections (a common technique used to introduce vectors into mouse models) (92). Cryo-fixation preserves extracellular space, especially notable at synapses and blood vessels (93). This method could be used to determine native folding and unfolding of proteins within microglia, to better understand their morphological and functional changes in various disease conditions.

\section{THE FUTURE OF EM AND MICROGLIA}

The past 15 years have seen a whirlwind in EM development. Previously, when investigating 3D ultrastructure, serial ultrathin sections were manually cut and collected at the ultramicrotome, imaged individually onto film under a TEM, and painstakingly reoriented and collated prior to analysis (94). As digital imaging improved, TEMs were outfitted with digital cameras allowing for faster imaging, but the electron beam of the TEM could still deform ultrathin sections, making perfect alignment of sequential sections almost impossible. Developments in SEM opened the door for array tomography studies on ribbons of serial ultrathin sections, allowing CLEM on the same tissue, and solving the problem of deformation introduced when using TEM (81).

The first major revolution in 3D ultrastructure imaging came when Denk and Horstmann engineered a working diamond knife 
TABLE 1 | Types of EM.

\begin{tabular}{|c|c|c|c|c|}
\hline Type of EM & Typical sample preparation & Maximal resolution & Advantages & Disadvantages \\
\hline $\begin{array}{l}\text { Transmission electron } \\
\text { microscopy (TEM) (49) }\end{array}$ & $\begin{array}{l}\text { - Fixation with aldehydes and plastic } \\
\text { resin embedding } \\
\text { - Manually cut ultramicrotomy (thin } \\
\text { sections of } 50-80 \mathrm{~nm} \text { stored on } \\
\text { metal grids) }\end{array}$ & $\begin{array}{l}\text { Nanometer resolution in } x, y \\
\text { Resolution in } z \text { limited by } \\
\text { section thickness }\end{array}$ & $\begin{array}{l}\text { - Tissue can be archived and } \\
\text { reimaged } \\
\text { - Block of tissue may be saved and } \\
\text { recut } \\
\text { - Highest resolution and } \\
\text { magnification } \\
\text { - Osmium fixation is not required }\end{array}$ & $\begin{array}{l}\text { - Biological specimens must be } \\
\text { fixed with gluteraldehyde or } \\
\text { acrolein } \\
\text { - Low throughput } \\
\text { - Electron beam can cause } \\
\text { deformation of ultrathin tissue } \\
\text { sections } \\
\text { - Smaller magnification range } \\
\text { (680x to greater than } 30,000 \times)\end{array}$ \\
\hline $\begin{array}{l}\text { Scanning transmission } \\
\text { electron microscopy } \\
\text { (STEM) (49) }\end{array}$ & $\begin{array}{l}\text { - Fixation with aldehydes, strong } \\
\text { post-fixation with osmium (OTO), } \\
\text { and plastic resin embedding } \\
\text { - Manually cut ultramicrotomy (thin } \\
\text { sections of } 50-80 \mathrm{~nm} \text { stored on } \\
\text { metal grids) }\end{array}$ & $\begin{array}{l}\text { Nanometer resolution in } x, y \\
\text { Resolution in } z \text { limited by } \\
\text { section thickness }\end{array}$ & $\begin{array}{l}\text { - } \text { Tissue can be archived and } \\
\text { reimaged } \\
\text { - Block of tissue may be saved and } \\
\text { recut } \\
\text { - Faster imaging throughput than } \\
\text { traditional TEM } \\
\text { - Large magnification range ( } 20 \times \text { to } \\
\text { greater than } 30,000 \times)\end{array}$ & $\begin{array}{l}\text { - Biological specimens must be } \\
\text { fixed with gluteraldehyde or } \\
\text { acrolein } \\
\text { - Stronger osmium fixation } \\
\text { required than traditional TEM } \\
\text { - Electron beam can cause } \\
\text { deformation of ultrathin tissue } \\
\text { sections } \\
\text { - Risk of tissue destruction is } \\
\text { higher than with traditional TEM }\end{array}$ \\
\hline $\begin{array}{l}\text { Scanning electron } \\
\text { microscopy (SEM) (80) }\end{array}$ & $\begin{array}{l}\text { - Dehydration } \\
\text { - Strong post-fixation with osmium } \\
\text { (ОTO) if material contrast } \\
\text { imaging is desired } \\
\text { - Entire specimen (entire insect, } \\
\text { dissected organ, etc.) mounted } \\
\text { on a stub of metal with adhesive } \\
\text { - Coated with a conductive metal }\end{array}$ & $\begin{array}{l}\text { Nanometer resolution in } x, y \text {, } \\
\text { and } z \text { for surface topography }\end{array}$ & $\begin{array}{l}\text { - Tissue can be archived and } \\
\text { reimaged } \\
\text { - Large magnification range }(20 \times \text { to } \\
\text { greater than } 30,000 \times) \\
\text { - Can create images of up to several } \\
\mathrm{cm}^{3} \text {, which provides a good } \\
\text { representation of the 3D shape of the } \\
\text { specimen } \\
\text { - Secondary electron detector } \\
\text { measures surface topography } \\
\text { - Backscatter electron detector } \\
\text { measures material contrast } \\
\text { (i.e., cell membrane versus } \\
\text { cytoplasm) }\end{array}$ & $\begin{array}{l}\text { - Biological specimens must be } \\
\text { fixed with gluteraldehyde or } \\
\text { acrolein } \\
\text { - Image is created using } \\
\text { scattered electrons and limited } \\
\text { to the surface of the specimen }\end{array}$ \\
\hline
\end{tabular}

\begin{tabular}{|c|c|c|c|c|}
\hline $\begin{array}{l}\text { Scanning electron } \\
\text { microscopy with array } \\
\text { tomography (81) }\end{array}$ & $\begin{array}{l}\text { - Fixation with aldehydes, strong } \\
\text { post-fixation with osmium (OTO), } \\
\text { and plastic resin embedding } \\
\text { - Manually or automatically cut } \\
\text { serial sections ultramicrotomy } \\
\text { (thin sections of } 50-80 \mathrm{~nm} \\
\text { stored on silicon chips or } \\
\text { magnetic tape) }\end{array}$ & $\begin{array}{l}\text { Nanometer resolution in } x, y \\
\text { Resolution in } z \text { limited by } \\
\text { section thickness }\end{array}$ & $\begin{array}{l}\text { - Tissue can be archived and } \\
\text { reimaged } \\
\text { - Image large and serial sections } \\
\text { - Large magnification range }(20 \times \text { to } \\
\text { greater than } 30,000 \times) \\
\text { - Compatible with correlative } \\
\text { light-EM imaging } \\
\text { - No deformation of tissue, making } \\
\text { serial reconstruction simpler }\end{array}$ & $\begin{array}{l}\text { - Serial section cutting and } \\
\text { collecting is technically } \\
\text { challenging } \\
\text { - Stronger fixation required for } \\
\text { proper material contrast }\end{array}$ \\
\hline $\begin{array}{l}\text { Focused-ion beam- } \\
\text { scanning electron } \\
\text { microscopy } \\
\text { (FIB-SEM) (82) }\end{array}$ & $\begin{array}{l}\text { - Fixation with aldehydes, strong } \\
\text { post-fixation with osmium (OTO), } \\
\text { and plastic resin embedding } \\
\text { - Prepared tissue specimen } \\
\text { (3-10 } \mathrm{mm}^{2} \text { wide } \times 3-10 \mathrm{~mm}^{2} \\
\text { tall } \times 50-75 \mu \mathrm{m} \text { thick) mounted } \\
\text { on a stub of metal with adhesive } \\
\text { - Coated with a conductive metal }\end{array}$ & $\begin{array}{l}\text { Nanometer resolution in } x, y \\
\text { Up to } 5 \mathrm{~nm} \text { resolution in } z \text { (83) }\end{array}$ & $\begin{array}{l}\text { - Nanometer resolution (less } \\
\text { than } 5 \mathrm{~nm} \text { per pixel) in all three } \\
\text { dimensions } \\
\text { - Simplest serial image } \\
\text { reconstruction }\end{array}$ & $\begin{array}{l}\text { - The entire tissue block must } \\
\text { be mounted and cannot be } \\
\text { resectioned } \\
\text { - Limited to a very small } \\
\text { area, usually less than } \\
15 \mu \mathrm{m} \times 15 \mu \mathrm{m} \\
\text { - Smaller magnification range } \\
\text { ( } 400 \times \text { to greater than } 30,000 \times) \\
\text { - The sample is destroyed as it is } \\
\text { imaged and cannot be reimaged }\end{array}$ \\
\hline CryoTEM (84) & - High-pressure freezing & Nanometer resolution in $x, y$ & - No fixation required & - Technically challenging \\
\hline CryoSEM (84) & $\begin{array}{l}\text { - Manually or automatically cut } \\
\text { sections using cryo- } \\
\text { ultramicrotomy (40-100 nm thick) }\end{array}$ & $\begin{array}{l}\text { Resolution in } z \text { limited to } \\
\text { section thickness }\end{array}$ & $\begin{array}{l}\text { - Allows imaging of specimens in a } \\
\text { native-like state }\end{array}$ & $\begin{array}{l}\text { - The sample must be flash- } \\
\text { frozen to preserve native protein } \\
\text { folding } \\
\text { - The sample must remain frozen } \\
\text { through entire process }\end{array}$ \\
\hline
\end{tabular}

Table of the major types of electron microscopy (EM) described in this mini-review, highlighting sample preparation, maximal resolution, magnification power, and advantages and disadvantages to each technique. Typical sample preparation is provided for each method, but fixation with aldehydes can be avoided if the researchers instead flash-freeze samples and perform freeze-substitution following sample collection. 
into the chamber of a SEM to perform serial block-face scanning electron microscope (SBEM) (95). With this approach, the block face is imaged, a 50-nm section is cut away, followed by another image. Peddie and Collinson recently reviewed the many types of 3D EM and its applications to biological tissues (96). A decade after SBEM was invented, it allowed researchers to confirm microglial synaptic stripping (97). Research in a mouse model of multiple sclerosis used SBEM to unravel different roles of microglia versus infiltrating monocytes very early in the disease. The authors performed SBEM and differentiated resident microglia from invading myeloid cells by their ultrastructural differences (changes in mitochondrial makeup, nuclear shape, and presence of osmiophilic granules) in order to determine that demyelination in experimental autoimmune encephalitis is initially performed by invading monocytes, while resident microglia did not contribute to the early stages of inflammation (98). More recently, focused-ion beam coupled with SEM (FIB-SEM) has improved resolution from $50 \mathrm{~nm}$ to less than $10 \mathrm{~nm}$ in the $z$-dimension (99). By employing a focused-ion beam to atomize a very thin layer from a small (usually less than $500 \mu \mathrm{m}^{2}$ ) area, researchers may image at $5 \mathrm{~nm}$ resolution in $x, y$, and $z(82)$.

Both SBEM and FIB-SEM are capable of investigating neuronal ultrastructure, and can follow a single process through several microns of neuropil, but FIB-SEM is also capable of resolving synaptic vesicles, lysosomes, and phagosomes in three dimensions. If the FIB-SEM process began within a microglial cell body, researchers could trace fine microglial processes through several microns of neuropil, without having to perform immunoEM. This offers a better chance to investigate lipidic inclusions and other pathological changes in organelles obscured by electrondense precipitates used in immunoEM.

In addition to technological advances in both SEM and TEM, the rapid development of cryoEM techniques described here could uncover native protein structures within microglia. It could additionally pave the way for discoveries into the snapshot of microglial-neuron and microglia-glia interactions

\section{REFERENCES}

1. Mariani MM, Kielian T. Microglia in infectious diseases of the central nervous system. J Neuroimmune Pharmacol (2009) 4:448-61. doi:10.4049/ jimmunol.178.9.5753

2. Witcher KG, Eiferman DS, Godbout JP. Priming the inflammatory pump of the CNS after traumatic brain injury. Trends Neurosci (2015) 38:609-20. doi:10.1016/j.tins.2015.08.002

3. Zarruk JG, Greenhalgh AD, David S. Microglia and macrophages differ in their inflammatory profile after permanent brain ischemia. Exp Neurol (2018) 301:120-32. doi:10.1016/j.expneurol.2017.08.011

4. Ransohoff RM. How neuroinflammation contributes to neurodegeneration. Science (2016) 353:777-83. doi:10.1126/science.aag2590

5. Wu Y, Dissing-Olesen L, MacVicar BA, Stevens B. Microglia: dynamic mediators of synapse development and plasticity. Trends Immunol (2015) 36:605-13. doi:10.1016/j.it.2015.08.008

6. del Rio-Hortega P. El tercer elemento de los centros nerviosos. I. La microglia en estado normal. II. Intervencion de la microglia en los procesos patologicos. III. Naturaleza probable de la microglia. Bol de la Soc Esp de Biol (1919) 8:69-120.

7. Sierra A, de Castro F, Del Río-Hortega J, Rafael Iglesias-Rozas J, Garrosa M, Kettenmann H. The "Big-Bang" for modern glial biology: translation and without requiring fixatives, and without the corresponding tissue deformation that occurs with rapid fixation currently required to preserve ultrastructure. While fixatives and ultrathin sections required for EM are not compatible with post-imaging analysis of RNA or proteins, future iterations of CLEM (perhaps cryoCLEM) and advances in single-cell mRNA isolation may be able to isolate subcellular tissue fractions for further analysis. Armed with these new tools, biologists may investigate the complex interactions between glia and neurons in a number of diseases. The unique nature of EM allows researchers to characterize unique ultrastructural characteristics of microglia and other immune cells, and uncover possible paths for therapeutic intervention.

\section{AUTHOR CONTRIBUTIONS}

JS and MET conceived the ideas and drafted the manuscript to which all authors contributed. KP and FG-I created the figures. All authors read and approved the final version of the manuscript.

\section{ACKNOWLEDGMENTS}

The authors would like to thank Kanchan Bisht, Kaushik Sharma, Marie-Kim St.-Pierre, and Hassan El-Hajj for providing EM images of microglia, as well as Nathalie Vernoux, Cynthia Lecours, and Julie-Christine Levesque for technical assistance. MET is a recipient of a Canada Research Chair (Tier 2) in Neuroimmune Plasticity in Health and Therapy, JS is a recipient of a Fonds de recherche du Québec-Santé (FRQS) fellowship, KP is the recipient of a Fondation du CHU de Québec scholarship, and FG-I is the recipient of a scholarship from Consejo Nacional de Ciencia y Tecnologia (Conacyt).

\section{FUNDING}

This work was funded by ERANET-Neuron Neuroinflammation (TracInflam).

comments on Pío del Río-Hortega 1919 series of papers on microglia. Glia (2016) 64:1801-40. doi:10.1111/ejn.13256

8. Rezaie P, Hanisch U-K. Historical context. In: Tremblay M-È, Sierra A, editors. Microglia in Health and Disease. New York, NY: Springer New York (2014). p. 7-46.

9. Tremblay M-Ė, Lecours C, Samson L, Sánchez-Zafra V, Sierra A. From the Cajal alumni Achúcarro and Río-Hortega to the rediscovery of never-resting microglia. Front Neuroanat (2015) 9:45. doi:10.3389/ fnana.2015.00045

10. Davalos D, Grutzendler J, Yang G, Kim JV, Zuo Y, Jung S, et al. ATP mediates rapid microglial response to local brain injury in vivo. Nat Neurosci (2005) 8:752-8. doi:10.1038/nn1472

11. Nimmerjahn A, Kirchhoff F, Helmchen F. Resting microglial cells are highly dynamic surveillants of brain parenchyma in vivo. Science (2005) 308:1314-8. doi:10.1126/science.1110647

12. Ginhoux F, Greter M, Leboeuf M, Nandi S, See P, Gokhan S, et al. Fate mapping analysis reveals that adult microglia derive from primitive macrophages. Science (2010) 330:841-5. doi:10.1126/science.1194637

13. Goldmann T, Wieghofer P, Müller PF, Wolf Y, Varol D, Yona S, et al. A new type of microglia gene targeting shows TAK1 to be pivotal in CNS autoimmune inflammation. Nat Neurosci (2013) 16:1618-26. doi:10.1038/ nn. 3531 
14. Parkhurst CN, Yang G, Ninan I, Savas JN, Yates JR, Lafaille JJ, et al. Microglia promote learning-dependent synapse formation through brain-derived neurotrophic factor. Cell (2013) 155:1596-609. doi:10.1016/j.cell.2013.11.030

15. Butovsky O, Siddiqui S, Gabriely G, Lanser AJ, Dake B, Murugaiyan G, et al. Modulating inflammatory monocytes with a unique microRNA gene signature ameliorates murine ALS. J Clin Invest (2012) 122:3063-87. doi:10.1172/ JCI62636

16. Hickman SE, Kingery ND, Ohsumi TK, Borowsky ML, Wang L-C, Means TK, et al. The microglial sensome revealed by direct RNA sequencing. Nat Neurosci (2013) 16:1896-905. doi:10.1038/nn.3554

17. Chiu IM, Morimoto ETA, Goodarzi H, Liao JT, O'Keeffe S, Phatnani HP, et al. A neurodegeneration-specific gene-expression signature of acutely isolated microglia from an amyotrophic lateral sclerosis mouse model. Cell Rep (2013) 4:385-401. doi:10.1016/j.celrep.2013.06.018

18. Zhang Y, Chen K, Sloan SA, Bennett ML, Scholze AR, O'Keeffe S, et al. An RNA-sequencing transcriptome and splicing database of glia, neurons, and vascular cells of the cerebral cortex. J Neurosci (2014) 34:11929-47. doi:10.1523/JNEUROSCI.1860-14.2014

19. Pocock JM, Kettenmann H. Neurotransmitter receptors on microglia. Trends Neurosci (2007) 30:527-35. doi:10.1016/j.tins.2007.07.007

20. Domercq M, Vázquez-Villoldo N, Matute C. Neurotransmitter signaling in the pathophysiology of microglia. Front Cell Neurosci (2013) 7:49. doi:10.3389/fncel.2013.00049

21. Tay TL, Savage J, Hui C-W, Bisht K, Tremblay M-Ė. Microglia across the lifespan: from origin to function in brain development, plasticity and cognition. J Physiol (2017) 595:1929-45. doi:10.1113/JP272134

22. Tremblay M-Ë, Lowery RL, Majewska AK. Microglial interactions with synapses are modulated by visual experience. PLoS Biol (2010) 8:e1000527. doi:10.1371/journal.pbio.1000527

23. Bethge P, Chéreau R, Avignone E, Marsicano G, Nägerl UV. Two-photon excitation STED microscopy in two colors in acute brain slices. Biophys $J$ (2013) 104:778-85. doi:10.1016/j.bpj.2012.12.054

24. Szalay G, Martinecz B, Lénárt N, Környei Z, Orsolits B, Judák L, et al. Microglia protect against brain injury and their selective elimination dysregulates neuronal network activity after stroke. Nat Commun (2016) 7:1-13. doi:10.1038/ncomms11499

25. Porrero C, Rubio-Garrido P, Avendaño C, Clascá F. Mapping of fluorescent protein-expressing neurons and axon pathways in adult and developing Thy1-eYFP-H transgenic mice. Brain Res (2010) 1345:59-72. doi:10.1016/j. brainres.2010.05.061

26. Lee S, Varvel NH, Konerth ME, Xu G, Cardona AE, Ransohoff RM, et al. CX3CR1 deficiency alters microglial activation and reduces beta-amyloid deposition in two Alzheimer's disease mouse models. Am J Pathol (2010) 177:2549-62. doi:10.2353/ajpath.2010.100265

27. Comley LH, Wishart TM, Baxter B, Murray LM, Nimmo A, Thomson D, et al. Induction of cell stress in neurons from transgenic mice expressing yellow fluorescent protein: implications for neurodegeneration research. PLoS One (2011) 6:e17639. doi:10.1371/journal.pone.0017639.t001

28. MacDonald L, Baldini G, Storrie B. Does super-resolution fluorescence microscopy obsolete previous microscopic approaches to protein co-localization? In: Tang B, editor. Methods in Molecular Biology. Membrane Trafficking. New York, NY: Springer New York (2015). p. 255-75.

29. Busch H. Über die Wirkungsweise der Konzentrierungsspule bei der Braunschen Röhre. Archiv für Elektrotechnik (1927) 18:583-94. doi:10.1007/ BF01656203

30. Knoll M, Ruska E. Das Elektronenmikroskop. Zeitschrift für Physik (1932) 78:318-39. doi:10.1007/BF01342199

31. Ardenne Von M, Beischer D. Untersuchung von Metalloxyd-Rauchen mit dem Universal-Elektronenmikroskop. Berichte der Bunsengesellschaft für physikalische Chemie (1940) 46:270-7. doi:10.1002/bbpc.19400460406

32. Luft JH. The use of acrolein as a fixative for light and electron microscopy. Anat Record (1959) 133:305.

33. Sabatini DD, Bensch K, Barrnett RJ. Cytochemistry and electron microscopy. The preservation of cellular ultrastructure and enzymatic activity by aldehyde fixation. J Cell Biol (1963) 17:19-58. doi:10.1083/jcb.17.1.19

34. Marton L. Electron microscopy of biological objects. Nature (1934) 133:911. doi:10.1038/133911b0
35. Palay SL, McGee-Russell SM, Gordon S, Grillo MA. Fixation of neural tissues for electron microscopy by perfusion with solutions of osmium tetroxide. J Cell Biol (1962) 12:385-410. doi:10.1083/jcb.12.2.385

36. Webster H, Collins GH. Comparison of osmium tetroxide and glutaraldehyde perfusion fixation for the electron microscopic stufy of the normal rat peripheral nervous system. J Neuropathol Exp Neurol (1964) 23:109-26. doi:10.1093/jnen/23.1.109

37. Williams TH, Jew JY. An improved method for perfusion fixation of neural tissues for electron microscopy. Tissue Cell (1975) 7:407-18. doi:10.1016/0040-8166(75)90015-4

38. Van Harreveld A, Crowell J, Malhotra SK. A study of extracellular space in central nervous tissue by freeze-substitution. J Cell Biol (1965) 25:117-37. doi:10.1083/jcb.25.1.117

39. Pallotto M, Watkins PV, Fubara B, Singer JH, Briggman KL. Extracellular space preservation aids the connectomic analysis of neural circuits. Elife (2015) 4. doi:10.7554/eLife.08206

40. Dubochet J, Adrian M, Chang JJ, Homo JC, Lepault J, McDowall AW, et al. Cryo-electron microscopy of vitrified specimens. Q Rev Biophys (1988) 21:129-228. doi:10.1017/S0033583500004297

41. Al-Amoudi A, Norlen LPO, Dubochet J. Cryo-electron microscopy of vitreous sections of native biological cells and tissues. J Struct Biol (2004) 148:131-5. doi:10.1016/j.jsb.2004.03.010

42. Cloutier N, Tan S, Boudreau LH, Cramb C, Subbaiah R, Lahey L, et al. The exposure of autoantigens by microparticles underlies the formation of potent inflammatory components: the microparticle-associated immune complexes. EMBO Mol Med (2012) 5:235-49. doi:10.1016/j.autrev.2005.03.005

43. Milasan A, Tessandier N, Tan S, Brisson A, Boilard E, Martel C. Extracellular vesicles are present in mouse lymph and their level differs in atherosclerosis. J Extracell Vesicles (2016) 5:31427. doi:10.1038/srep27862

44. Pease DC, Baker RF. Sectioning techniques for electron microscopy using a conventional microtome. Exp Biol Med (1948) 67:470-4. doi:10.3181/ 00379727-67-16344

45. Fernández-Morán H. A diamond knife for ultrathin sectioning. Exp Cell Res (1953) 5:255-6. doi:10.1016/0014-4827(53)90112-8

46. Sjöstrand FS. A new microtome for ultrathin sectioning for high resolution electron microscopy. Experientia (1953) 9:114-5. doi:10.1007/ $\mathrm{BF} 02178346$

47. Fernández-Morán H. Applications of a diamond knife for ultrathin sectioning to the study of the fine structure of biological tissues and metals. J Biophys Biochem Cytol (1956) 2:29-30. doi:10.1083/jcb.2.4.29

48. Tremblay M-Ė, Riad M, Majewska A. Preparation of mouse brain tissue for immunoelectron microscopy. J Vis Exp (2010) (41):e2021. doi:10.3791/2021

49. Winey M, Meehl JB, O’Toole ET, Giddings TH. Conventional transmission electron microscopy. Mol Biol Cell (2014) 25:319-23. doi:10.1083/ jcb.148.4.635

50. Bisht K, Hajj El H, Savage JC, Sánchez MG, Tremblay M-Ė. Correlative light and electron microscopy to study microglial interactions with $\beta$-amyloid plaques. J Vis Exp (2016) (112):e54060. doi:10.3791/54060

51. Schultz RL, MAYNARD EA, Pease DC. Electron microscopy of neurons and neuroglia of cerebral cortex and corpus callosum. Am J Anat (1957) 100:369-407. doi:10.1002/aja.1001000305

52. Blinzinger K, Kreutzberg G. Displacement of synaptic terminals from regenerating motoneurons by microglial cells. Z Zellforsch Mikrosk Anat (1968) 85:145-57. doi:10.1007/BF00325030

53. Giulian D, Baker TJ. Characterization of ameboid microglia isolated from developing mammalian brain. JNeurosci (1986) 6:2163-78. doi:10.1523/ JNEUROSCI.06-08-02163.1986

54. Mori S, Leblond CP. Identification of microglia in light and electron microscopy. J Comp Neurol (1969) 135:57-80. doi:10.1002/cne.901350104

55. García-Cabezas MÁ, John YJ, Barbas H, Zikopoulos B. Distinction of neurons, glia and endothelial cells in the cerebral cortex: an algorithm based on cytological features. Front Neuroanat (2016) 10:107. doi:10.3389/ fnana.2016.00107

56. Herndon RM. The fine structure of the rat cerebellum. II The stellate neurons, granule cells, and glia. J Cell Biol (1964) 23:277-93. doi:10.1083/jcb.23.2.277

57. Shapiro LA, Perez ZD, Foresti ML, Arisi GM, Ribak CE. Morphological and ultrastructural features of Ibal-immunolabeled microglial cells in the 
hippocampal dentate gyrus. Brain Res (2009) 1266:29-36. doi:10.1016/j. brainres.2009.02.031

58. Peinado MA, Quesada A, Pedrosa JA, Torres MI, Martinez M, Esteban FJ, et al. Quantitative and ultrastructural changes in glia and pericytes in the parietal cortex of the aging rat. Microsc Res Tech (1998) 43:34-42. doi:10.1002/ (SICI) 1097-0029(19981001)43:1<34:AID-JEMT6>3.0.CO;2-G

59. Murabe Y, Sano Y. Morphological studies on neuroglia. V. Microglial cells in the cerebral cortex of the rat, with special reference to their possible involvement in synaptic function. Cell Tissue Res (1982) 223:493-506.

60. Almolda B, González B, Castellano B. Microglia detection by enzymatic histochemistry. In: Joseph B, Venero JL, editors. Microglia: Methods and Protocols. Totowa, NJ: Humana Press (2013). p. 243-59.

61. Tremblay M-Ė, Zhang I, Bisht K, Savage JC, Lecours C, Parent M, et al. Remodeling of lipid bodies bydocosahexaenoic acid in activatedmicroglial cells. J Neuroinflammation (2016) 13:116. doi:10.1186/s12974-016-0580-0

62. Ito D, Imai Y, Ohsawa K, Nakajima K, Fukuuchi Y, Kohsaka S. Microgliaspecific localisation of a novel calcium binding protein, Iba1. Brain Res Mol Brain Res (1998) 57:1-9. doi:10.1016/S0169-328X(98)00040-0

63. Wake H, Moorhouse AJ, Jinno S, Kohsaka S, Nabekura J. Resting microglia directly monitor the functional state of synapses in vivo and determine the fate of ischemic terminals. J Neurosci (2009) 29:3974-80. doi:10.1523/ JNEUROSCI.4363-08.2009

64. Watts RJ, Schuldiner O, Perrino J, Larsen C, Luo L. Glia engulf degenerating axons during developmental axon pruning. Curr Biol (2004) 14:678-84. doi:10.1016/j.cub.2004.03.035

65. van Ham TJ, Brady CA, Kalicharan RD, Oosterhof N, Kuipers J, VeenstraAlgra A, et al. Intravital correlated microscopy reveals differential macrophage and microglial dynamics during resolution of neuroinflammation. Dis Model Mech (2014) 7:857-69. doi:10.1242/dmm.014886

66. Paolicelli RC, Bolasco G, Pagani F, Maggi L, Scianni M, Panzanelli P, et al. Synaptic pruning by microglia is necessary for normal brain development. Science (2011) 333:1456-8. doi:10.1126/science.1202529

67. Schafer DP, Lehrman EK, Kautzman AG, Koyama R, Mardinly AR, Yamasaki R, et al. Microglia sculpt postnatal neural circuits in an activity and complement-dependent manner. Neuron (2012) 74:691-705. doi:10.1016/j. neuron.2012.03.026

68. Squarzoni P, Oller G, Hoeffel G, Pont-Lezica L, Rostaing P, Low D, et al. Microglia modulate wiring of the embryonic forebrain. Cell Rep (2014) 8:1271-9. doi:10.1016/j.celrep.2014.07.042

69. Sisková Z, Page A, O’Connor V, Perry VH. Degenerating synaptic boutons in prion disease. Am J Pathol (2009) 175:1610-21. doi:10.2353/ ajpath.2009.090372

70. Seeger G, Härtig W, Rossner S, Schliebs R, Brückner G, Bigl V, et al. Electron microscopic evidence for microglial phagocytic activity and cholinergic cell death after administration of the immunotoxin 192IgG-saporin in rat. J Neurosci Res (1997) 48:465-76. doi:10.1002/(SICI)1097-4547(19970601) 48:5<465::AID-JNR7>3.0.CO;2-C

71. Chung W-S, Clarke LE, Wang GX, Stafford BK, Sher A, Chakraborty C, et al. Astrocytes mediate synapse elimination through MEGF10 and MERTK pathways. Nature (2013) 504:394-400. doi:10.1038/nature12776

72. Bisht K, Sharma KP, Lecours C, Gabriela Sánchez M, Hajj El H, Milior G, et al. Dark microglia: a new phenotype predominantly associated with pathological states. Glia (2016) 64:826-39. doi:10.1002/glia.22966

73. Hui C-W, St-Pierre A, Hajj El H, Remy Y, Hebert SS, Luheshi G, et al. Prenatal immune challenge in mice leads to partly sex-dependent behavioral, microglial, and molecular abnormalities associated with schizophrenia. Front Mol Neurosci (2018) 11:13. doi:10.3389/fnmol.2018.00013

74. Streit WJ, Xue Q-S, Tischer J, Bechmann I. Microglial pathology. Acta Neuropathol Commun (2014) 2:142. doi:10.1186/s40478-014-0142-6

75. Milior G, Lecours C, Samson L, Bisht K, Poggini S, Pagani F, et al. Fractalkine receptor deficiency impairs microglial and neuronal responsiveness to chronic stress. Brain Behav Immun (2016) 55:114-25. doi:10.1016/j.bbi.2015.07.024

76. Tseng CY, Ling EA, Wong WC. Light and electron microscopic and cytochemical identification of amoeboid microglial cells in the brain of prenatal rats. J Anat (1983) 136:837-49.

77. Le Guellec D. Ultrastructural in situ hybridization: a review of technical aspects. Biol Cell (1998) 90:297-306. doi:10.1111/j.1768-322X.1998.tb01040.x
78. Cubas-Nuñez L, Duran-Moreno M, Castillo-Villalba J, Fuentes-Maestre J, Casanova B, García-Verdugo JM, et al. In situ RT-PCR optimized for electron microscopy allows description of subcellular morphology of target mRNA-expressing cells in the brain. Front Cell Neurosci (2017) 11:141. doi:10.3389/fncel.2017.00141

79. Tischer J, Krueger M, Mueller W, Staszewski O, Prinz M, Streit WJ, et al. Inhomogeneous distribution of Iba-1 characterizes microglial pathology in Alzheimer's disease. Glia (2016) 64:1562-72. doi:10.1002/glia.23024

80. Vernon-Parry KD. Scanning electron microscopy: an introduction. III-Vs Review (2000) 13:40-4. doi:10.1016/S0961-1290(00)80006-X

81. Micheva KD, Smith SJ. Array tomography: a new tool for imaging the molecular architecture and ultrastructure of neural circuits. Neuron (2007) 55:25-36. doi:10.1016/j.neuron.2007.06.014

82. Knott G, Marchman H, Wall D, Lich B. Serial section scanning electron microscopy of adult brain tissue using focused ion beam milling. J Neurosci (2008) 28:2959-64. doi:10.1523/JNEUROSCI.3189-07.2008

83. Maco B, Cantoni M, Holtmaat A, Kreshuk A, Hamprecht FA, Knott GW. Semiautomated correlative 3D electron microscopy of in vivo-imaged axons and dendrites. Nat Protoc (2014) 9:1354-66. doi:10.1038/ nprot.2014.101

84. Thompson RF, Walker M, Siebert CA, Muench SP, Ranson NA. An introduction to sample preparation and imaging by cryo-electron microscopy for structural biology. Methods (2016) 100:3-15. doi:10.1016/j.ymeth. 2016.02.017

85. van Rijnsoever C, Oorschot V, Klumperman J. Correlative light-electron microscopy (CLEM) combining live-cell imaging and immunolabeling of ultrathin cryosections. Nat Meth (2008) 5:973-80. doi:10.1038/nmeth.1263

86. Knott GW, Holtmaat A, Wilbrecht L, Welker E, Svoboda K. Spine growth precedes synapse formation in the adult neocortex in vivo. Nat Neurosi (2006) 9:1117-24. doi:10.1038/nn1747

87. Majewska AK, Lamantia CE, Kelly EA, Sipe GO, Tremblay M-E, Lowery RL. Microglial P2Y12 is necessary for synaptic plasticity in mouse visual cortex. Nat Commun (2016) 7:10905. doi:10.1038/ncomms10905

88. Vasek MJ, Garber C, Dorsey D, Durrant DM, Bollman B, Soung A, et al. A complement-microglial axis drives synapse loss during virus-induced memory impairment. Nature (2016) 534:538-43. doi:10.1038/nature18283

89. Bechmann I, Nitsch R. Astrocytes and microglial cells incorporate degenerating fibers following entorhinal lesion: a light, confocal, and electron microscopical study using a phagocytosis-dependent labeling technique. Glia (1997) 20:145-54. doi:10.1002/(SICI)1098-1136(199706) 20:2<145:AID-GLIA6>3.0.CO;2-8

90. Ibiricu I, Huiskonen JT, Döhner K, Bradke F, Sodeik B, Grünewald K. Cryo electron tomography of herpes simplex virus during axonal transport and secondary envelopment in primary neurons. PLoS Pathog (2011) 7:e1002406. doi:10.1371/journal.ppat.1002406.s002

91. Fernandez-Fernandez MR, Ruiz-Garcia D, Martin-Solana E, Chichon FJ, Carrascosa JL, Fernandez J-J. 3D electron tomography of brain tissue unveils distinct Golgi structures that sequester cytoplasmic contents in neurons. J Cell Sci (2017) 130:83-9. doi:10.1242/jcs.188060

92. Weil M-T, Ruhwedel T, Möbius W, Simons M. Intracerebral injections and ultrastructural analysis of high-pressure frozen brain tissue. Curr Protoc Neurosci (2017) 78:2.27.1-2.27.18. doi:10.1002/cpns.22

93. Korogod N, Petersen CCH, Knott GW. Ultrastructural analysis of adult mouse neocortex comparing aldehyde perfusion with cryo fixation. Elife (2015) 4. doi:10.7554/eLife.05793

94. Fiala JC, Harris KM. Extending unbiased stereology of brain ultrastructure to three-dimensional volumes. J Am Med Inform Assoc (2001) 8:1-16. doi:10.1136/jamia.2001.0080001

95. Denk W, Horstmann H. Serial block-face scanning electron microscopy to reconstruct three-dimensional tissue nanostructure. PLoS Biol (2004) 2:e329. doi:10.1371/journal.pbio.0020329.s002

96. Peddie CJ, Collinson LM. Exploring the third dimension: volume electron microscopy comes of age. Micron (2014) 61:9-19. doi:10.1016/j. micron.2014.01.009

97. Chen Z, Jalabi W, Hu W, Park H-J, Gale JT, Kidd GJ, et al. Microglial displacement of inhibitory synapses provides neuroprotection in the adult brain. Nat Commun (2014) 5:4486. doi:10.1038/ncomms5486 
98. Yamasaki R, Lu H, Butovsky O, Ohno N, Rietsch AM, Cialic R, et al. Differential roles of microglia and monocytes in the inflamed central nervous system. J Exp Med (2014) 211:1533-49. doi:10.1182/blood-2009-02-200543

99. Heymann JAW, Hayles M, Gestmann I, Giannuzzi LA, Lich B, Subramaniam S. Site-specific 3D imaging of cells and tissues with a dual beam microscope. J Struct Biol (2006) 155:63-73. doi:10.1016/j.jsb.2006.03.006

100. Wolpers C. Electron microscopy in Berlin 1928-1945. Adv Electron Electron Phys (1991) 81:211-29. doi:10.1016/S0065-2539(08)60866-5

101. Farquhar MG, Hartmann JF. Neuroglial structure and relationships as revealed by electron microscopy. J Neuropathol Exp Neurol (1957) 16:18-39. doi:10.1097/00005072-195701000-00003

102. De Rosier DJ, Klug A. Reconstruction of three dimensional structures from electron micrographs. Nature (1968) 217:130. doi:10.1038/217130a0

103. Nobelprize.org. Press Release: The 1986 Nobel Prize in Physics. Nobel Media AB (2014). Available from: http://www.nobelprize.org/nobel_prizes/physics/ laureates/1986/press.html (Accessed: April 6, 2018).

104. Henderson R, Baldwin JM, Ceska TA, Zemlin F, Beckmann E, Downing KH. Model for the structure of bacteriorhodopsin based on high-resolution electron cryo-microscopy. J Mol Biol (1990) 213:899-929. doi:10.1016/S0022-2836(05)80271-2
105. Humphry MJ, Kraus B, Hurst AC, Maiden AM, Rodenburg JM Ptychographic electron microscopy using high-angle dark-field scattering for sub-nanometre resolution imaging. Nat Commun (2012) 3:730. doi:10.1038/ ncomms 1733

106. Nobelprize.org. The 2017 Nobel Prize in Chemistry - Press Release. Nobel Media AB (2014). Available from: http://www.nobelprize.org/nobel_prizes/ chemistry/laureates/2017/press.html (Accessed: April 6, 2018).

Conflict of Interest Statement: The authors declare that the research was conducted in the absence of any commercial or financial relationships that could be construed as a potential conflict of interest.

The handling Editor declared a past co-authorship with one of the authors MET.

Copyright (C) 2018 Savage, Picard, González-Ibáñez and Tremblay. This is an open-access article distributed under the terms of the Creative Commons Attribution License (CC BY). The use, distribution or reproduction in other forums is permitted, provided the original author(s) and the copyright owner are credited and that the original publication in this journal is cited, in accordance with accepted academic practice. No use, distribution or reproduction is permitted which does not comply with these terms. 